\title{
sciendo
}

\section{The Effects of Circuit Strength Training on the Development of Physical Fitness and Performance-Related Variables in Handball Players}

\author{
by \\ Souhail Hermassi ${ }^{1}$, Kevin Laudner ${ }^{2}$, René Schwesig ${ }^{3}$
}

The purpose of this study was to determine the effects of 12 weeks of circuit training on physical fitness in handball players. Subjects were randomly divided into a circuit strength training group $(C T, n=10)$ and a control group (CG, $n=9$ ). Training sessions and matches were performed together, but during the 12-week intervention, the experimental group replaced part of the regular regimen with circuit strength training. Measures assessed in both groups before and after the intervention included: the agility T-half Test, the Yo-Yo intermittent recovery test, squat and countermovement jumps, $15 \mathrm{~m}$ and $30 \mathrm{~m}$ sprints, and strength tests for the bench press, pull over, and the half squat. The upper limb bench press and pull-over tests along with the lower limb back half squat were performed using a 1-repetition maximum protocol. Based on the intraclass correlation coefficient and excluding the agility T-test $($ ICC $=0.72)$, we found excellent relative reliability for all variables (intraclass correlation coefficient range: 0.85-0.96, SEM range: 0.03-3.00). For absolute reliability or coefficients of variation, $71 \%(5 / 7)$ of the variables were excellent $(C V<5 \%)$. The circuit strength training group showed significant interaction effects and relevant effect sizes for the 12-week training period $(8 / 9,89 \%)$, and the mean effect size for the CT was markedly higher ( $d=1.3$, range: $0.41-2.76)$ than in the $C G(d=-$ 1.0 , range: $-0.73-0.29)$. The largest improvements were in the Yo-Yo test $(d=2.76)$ and the squat jump $(d=2.05)$. These results show that a 12-week circuit strength training program is an effective method to increase handball-related performance characteristics.

Key words: conditioning program; circuit training; handball; vertical jump, physical fitness.

\section{Introduction}

Handball is an intermittent sport, characterized by an alternation of high- and lowintensity activities, including sprints, jumps, and many changes of direction. However, players also need strength and power for running, jumping, and catching the ball before an opponent can score (Fieseler et al., 2017; Hermassi et al., 2017) Therefore, optimal conditioning programs should include strength training sessions. These may include isometrics, dynamic constant external resistance training, and isokinetics (Wilson et al., 1993). Other options include complex training (an alternation of high-load weight training with plyometric exercises) and contrast training (an alternation of high and low loads) (Maio Alves et al., 2010). Cometti et al. (1999) defined their contrast training program as the use of high loads (2-4 sets of 6 repetitions with loads between 60 and $80 \%$ of the 1-repetition maximum (1RM)) and low loads (4-6 sets of 6-12 repetitions with loads between 30 and $50 \%$ of $1 \mathrm{RM}$ ), with both types of sets performed at maximum speed.

Research on strength training in soccer players has shown that both increases and decreases in performance-related variables may result from different methods of training. Hermassi et al. (2017) and Fieseler et al. (2017)

\footnotetext{
1 - Sport Science Program, College of Arts and Sciences, Qatar University, Doha, Qatar.

2 - Department of Health Sciences, University of Colorado Coloardo Springs, Colorado Springs, CO, USA.

3 - Department of Orthopaedic and Trauma Surgery, Martin-Luther-University Halle-Wittenberg, Halle, Germany.
} 
observed significant increases in sprinting, jumping, and power as evaluated by the forcevelocity test after 8 weeks of half-squat strength training in junior soccer players. Chelly et al. (2010) also showed increases in peak power, jump force, jump height, and lower-limb muscle volume in junior soccer players, with gains in 5 to $40 \mathrm{~m}$ sprint velocities after an 8-week plyometric training program that involved hurdling and depth jumping. In contrast, Herrero et al. (2006) found no significant gains in 20-m sprint times following 4 weeks of plyometric training that was combined with electromyographic stimulation.

Maio Alves et al. (2010) suggested that complex contrast training was an adequate tactic to develop muscle power and speed in soccer players. However, no previous studies have examined the effects of contrast-resistance strength training on physical fitness and performance-related variables in handball players. Therefore, the purpose of the present study was to determine whether circuit training would improve strength, agility, intermittent aerobic capacity and vertical jump performance in handball players at a crucial phase in their playing season. We tested the hypothesis that incorporating 12-week contrast-resistance strength training into a standard training regimen would enhance each of these measures.

\section{Methods}

\section{Participants}

All procedures were approved by the Institutional Review Committee (Research Unit Sport Performance, Health \& Society) for the ethical use of human subjects, according to current national laws and regulations. Signed informed consent was provided by all participants (19 elite male handball players, age: $18.5 \pm 0.85$ years, body height: $1.81 \pm 0.06 \mathrm{~m}$, body mass: $88.01 \pm 14.56 \mathrm{~kg}$, training experience: $7.21 \pm 1.08$ years) and their parent or guardian after they had received both a verbal and a written explanation of the experimental protocol and its potential risks and benefits. Participants were informed that they could withdraw from the study without any consequence at any time. Examination by the team physician excluded orthopedic and other pathologies that might have contra-indicated resistance training. Participants were randomly assigned to one of the two groups, i.e., an experimental group (a circuit training group, CT $(\mathrm{n}=10))$, and a control group (a group that followed a standard in-season regimen, $C G(\mathrm{n}=9))$.

\section{Study Design}

This study was designed to address the following research question: to what extent may 12 weeks of in-season biweekly circuit training enhance strength, agility, high intensity aerobic capacity, sprint ability, and vertical jump performance in handball players? A team of players was randomly divided into the control (standard in-season regimen), and the experimental group. They completed familiarization trials prior to the initiation of testing (4 months into the playing season). Data were collected immediately before and after the 12week intervention. A standardized warm-up was performed before each testing session. The half back-squat were completed on Day 1. Day 2 was used for recovery. On Day 3, the $15 \mathrm{~m}$ and $30 \mathrm{~m}$ sprint as well as the 1RM pull-over test were performed. Day 4 was also used for rest, and on Day 5 the squat and counter-movement jumps along with the Yo-Yo intermittent recovery test were performed. On Day 6 participants completed the bench press and the T-half agility test.

Testing sessions were carried out at the same time of day and under the same experimental conditions, at least 3 days after the participants' most recent competition. Standard intake of food and fluids was maintained during the experiment, but physical exercise was avoided for one day before testing. Caffeine-containing beverages were prohibited for 4 hours and no food was consumed for 2 hours before testing. All participants had at least 7 hours of sleep at night throughout the investigation, and verbal encouragement was used for maximal effort throughout testing.

\section{Measures}

The intervention took place over a 12-week period from January to March, a time considered as crucial in maximizing physical fitness of the players. All participants had engaged in the same training sessions from the beginning of the competitive season (September); these were comprised of handball training 4-5 times per week and one official game per week. Practices lasted 90 minutes and usually focused on skill activities at various intensities and offensive and defensive tactics, plus 25-30 minutes of continuous play with the coach making only brief interruptions for instruction. The controls maintained this normal 
frequency of training, while the experimental group, during the 12-week intervention, replaced their technical-tactical skill training by circuit training twice per week. Its prescription was designed to maximize physical fitness.

One repetition maximum half back-squat

Participants maintained an upright position throughout this test. The bar was grasped firmly with both hands and was supported on the shoulders. The knees were bent to $90^{\circ}$ and the upright position was then regained, with the legs fully extended. A preliminary familiarization session determined the approximate $1 \mathrm{RM}$ value for each participant. Prior to each session, players performed a warm-up for 5 minutes on a cycle ergometer. In addition, the warm up also included a set of five repetitions of the half-back squat at loads of $40-60 \%$ of the players' pre-test 1RM, and prior to testing at 80 or $90 \%$ of their $1 \mathrm{RM}$. The barbell was then loaded to $90 \%$ of the pretest 1RM. Two consecutive tests were carried out, and if 2 repetitions were completed, a load of $5 \mathrm{~kg}$ was added after a recovery interval of 3 minutes. When the participant had performed 2 successful repetitions of his pretest RM value, further loads of $1 \mathrm{~kg}$ were added after the recovery interval. If the second repetition could not be completed with the new loading, the corresponding load was considered as the individual's 1RM (Hermassi et al., 2011). The average number of attempts needed to reach the 1 RM was 3 to 6 .

\section{Sprint performance}

Prior to sprint testing, each participant performed a 5-min warm up consisting of three minutes of running, change of direction activities and dynamic stretching. Within the last two minutes, there were two practice sprint starts of $3-$ $4 \mathrm{~s}$ duration (at 3.5 and $4.5 \mathrm{~min}$ ). Participants began the tests with their front foot $0.2 \mathrm{~m}$ behind the starting photocell beam (Microgate, Bolzano, Italy), and performance was timed over distances of $15 \mathrm{~m}$ and $30 \mathrm{~m}$. Three trials for each distance were separated by 6-8 min of recovery, with the best results registered for further analysis.

One repetition maximum pull-over

The bar was positioned $0.2 \mathrm{~m}$ above the participant's chest and was supported by the bottom stops of the weight rack. Successive eccentric-concentric contractions were performed from the starting position as described by Hermassi et al. (2010). All participants were familiar with the technique of execution, having used it in their weekly training sessions. A pre-test assessment of the 1RM pull-over (1RMPO) was made during the final standard training session. Prior to each session, athletes performed a 5-min warm-up that consisted of running, dynamic activities and stretching. This warm up also included a set of five repetitions at loads of $40-60 \%$ of their pre-test 1RM. Thereafter, four to five separate attempts were performed until the player was unable to extend the arms fully on two occasions. Two minutes of rest were allowed between trials. The load noted at the last acceptable extension was considered as the 1RMro.

Squat and counter movement jumps

Three trials were allowed for each test, with recovery intervals of $3 \mathrm{~min}$. Squat and counter-movement jump variables (jump height, maximal force before take-off, maximal velocity before take-off and average power of the jump) were determined using a force plate (Quattro Jump, version 1.04, Kistler Instrument AG, Winterthur, Switzerland). Jump height was determined as the center of mass displacement, calculated from the recorded force and body mass. For the squat jumps, participants first flexed their knees to $90^{\circ}$, then they powerfully extended their hips and knees, moving into a maximal vertical jump. The counter-movement jump started from an upright position; they performed a rapid downward squat movement to $\sim 90^{\circ}$ flexion, followed by a rapid extension of the legs. The hands were kept on the hips for both tests. Participants followed a similar general warm-up procedure that included $5 \mathrm{~min}$ of cycling with a 60 W load, stretching of lower limbs muscles (gastrocnemious, quadriceps, hip flexors, hamstrings and gluteals) and 2 min of jumping exercises. Players performed stretching exercises twice holding each stretch for $15 \mathrm{~s}$ and alternating between each leg in order to give adequate recovery before the next repetition. Jumping exercises included skipping $(6 \mathrm{~m})$, double limb ankle hops (6 reps), split squat jump (5 reps) and standing jump and reach (5 reps).

The Yo-Yo intermittent recovery test Level 1

The Yo-Yo test was performed as described by Krustrup et al. (2003). A standardized warm up prior to testing was comprised of $10 \mathrm{~min}$ of low-intensity running (involving basic runthroughs at an increasing tempo, dynamic 
stretching and change of direction activities). During testing, $20 \mathrm{~m}$ shuttle runs were performed at increasing velocities until exhaustion, with $10 \mathrm{~s}$ rest intervals of active recovery ( $2 \times 5 \mathrm{~m}$ of jogging) between runs. The test was concluded when the participant twice failed to reach the front line in time (objective evaluation) or felt unable to complete another shuttle at the required speed (subjective evaluation). The total distance covered was considered as the test "score".

One repetition maximum bench press

Maximal strength of the upper extremity was assessed using a one repetition maximum successive eccentric-concentric bench press (1RMвр) as described by Krustrup et al. (2003). Participants performed a warm-up for 5 minutes on a cycle ergometer. This warm up also included a set of five repetitions at loads of $40-60 \%$ of the pre-test 1-RM. During testing, players were in the supine position, with the bar positioned $10 \mathrm{~mm}$ above the chest and supported by the bottom stops of the weight rack. $90^{\circ}$ shoulder abduction was maintained while participants performed a concentric motion of horizontal shoulder adduction and elbow extension. No bouncing or arching of the back was allowed. Four to five separate attempts with 2 min rest intervals were completed, until the prticipant was unable to extend the arms fully. The last acceptable extension was recorded as the $1 \mathrm{RM} \mathrm{BP}$.

Agility T-half test

The T-half test (Sassi et al., 2009) was performed using the T-test protocol, except that the total distance covered was reduced from 36.6 to 20 $\mathrm{m}$. Data were recorded using an electronic timing system (Globus, Microgate; SARL, Italy) (Sassi et al., 2009). A 15-min warm-up that included jogging, lateral displacement, dynamic stretching and jumping was carried out. Testing began with both feet placed behind the starting line. Participants sprinted forward to a cone, touching its base with their right hand. Facing forward and without crossing feet, they then shuffled to the left to the next cone, touching its base with their left hand. They then shuffled to the right to a third cone, touching its base with their right hand, subsequently shuffling left back to the second cone and touching its base. Finally, they ran backwards as quickly as possible, returning to the starting line. Any player who crossed one foot in front of the other, failed to touch the base of a cone, and/or failed to face forward throughout had to repeat the test. Three minutes of rest were allowed between trials (Sassi et al., 2009).

Circuit-strength training

Each Tuesday and Thursday for 3 months, part of the experimental group's standard training regimen was replaced by circuit training (Table 1), performed immediately before the standard training sessions. Loads were calculated using the individual's previously measured $1 \mathrm{RM}$ and were verified after 4 and 8 weeks of the resistancetraining program. All training sessions were supervised by certified strength and conditioning specialists knowledgeable in weightlifting. Participants were encouraged to increase the weights lifted and to achieve concentric failure within each designated repetition range, and all completed a minimum of $95 \%$ of scheduled sessions. Each training session started with a standardized warm-up including jogging, dynamic stretching exercises, calisthenics, and preparatory exercises (e.g., fundamental weightlifting exercises specific to their training program), and ended with $5 \mathrm{~min}$ of cool-down activities including dynamic stretching. During the experimental protocol, all players participated in technical drills and tactical training. There were two sets for each sequence with 3 min rest interval between each sequence. During the training sessions, maximal effort was encouraged verbally. No injuries were encountered over the 24 sessions. Statistical Analyses

All statistical analyses were performed using SPSS version 25.0 for Windows (SPSS Inc., Chicago, IL, USA). Means and standard deviations of dependent variables were calculated for all handball players. Differences between groups (CT vs. CG) and sessions (pre- vs. post-intervention) were tested using a two-factor (time, group) univariate general linear model (Bortz et al., 1990). The effect size (d) (mean difference of scores divided by the pooled standard deviation) was calculated for each variable. Since multiple tests were used, the alpha level was adjusted using a standard Bonferroni correction ( $p=0.05 / 7$, or $p=$ 0.007 and $\eta^{2}>0.20$ and $d \geq 0.5$ ) to protect against Type I errors (Bortz et al., 1990). Due to the relatively small number of participants, decisions on significance were based on all three statistical values. A power calculation (nQuery Advisor 4.0; Statistical Solutions, Saugus, MA) showed that 
with a sample size of 7 in each group, the study had $80 \%$ power to detect a difference between means of $3.0 \mathrm{~cm}$ (main outcome: CMJ height) using a twosided t-test with a significance level of $p<0.05$, and assuming a common standard deviation of $2.0 \mathrm{~cm}$ (Bortz, 1999).

The intraclass correlation coefficient (ICC), coefficient of variation $(\mathrm{CV})$ and standard error of measurement (SEM) were calculated to describe test-retest reliability (Schrama et al., 2014). Interpretation of reliability values was based on guidelines provided by Portney and Watkins (2009), Shrout and Fleiss (1979) and Hopkins (2000). The ICC indicated an excellent relative reliability when the value was above 0.75 , fair-togood reliability between 0.40 and 0.75 , and poor reliability when less than 0.40 (Shrout and Fleiss, 1979). For intraobserver reliability, the mean intraclass correlation was calculated. ICC values may be influenced by inter-subject variability of scores, because a large ICC may be reported despite poor trial-to-trial consistency if the intersubject variability is too high (Portney and Watkins, 2009; Weir, 2005). However, the SEM is not affected by inter-subject variability (Weir, 2005). Therefore, SEM was reported in conjunction with the ICCs using the following equation from Portney and Watkins (2009):

$$
S E M=S D \times \sqrt{(1-I C C)}
$$

The $\mathrm{CV}$, an indicator of measurement variability and random error, was derived from log-transformed data (Hopker et al., 2010). The 95\% CIs were calculated for each CV and ICC.

\section{Results}

Prior to the intervention, all tests were evaluated concerning intrarater reliability. Based on the recommendation (ICC $\geq 0.75$ ) of Shrout and Fleiss (1979), 86\% (6/7) of all tests showed high reliability, except for the agility $\mathrm{T}$-test that displayed a lower level of reliability (ICC $=0.72$; Table 2). The values of absolute reliability (CV) were similar compared to the relative reliability (ICC). Only the strength variables (bench press, pull over) showed a $\mathrm{CV}$ above $5 \%$. The SEM ranged from $0.03 \mathrm{~m}$ (sprint $30 \mathrm{~m}$ ) to $3.00 \mathrm{~kg}$ (bench press).

We found significant interaction effects (group $x$ time) for the 12 week intervention in eight of the nine investigated performance variables
(Tables 3 and 4). Only the $30 \mathrm{~m}$ sprint $\left(p<0.001, \eta^{2}\right.$ $=0.555)$ and the strength test (bench press) $(p=$ $0.007, \eta^{2}=0.353$ ) displayed a significant inter-group difference. All intervention effects were higher than 0.4 for the CT. The largest effects and highest improvements were detected for distance covered during the Yo-Yo IR1 $(\mathrm{d}=2.76$; Table 3) and for squat-jump height $(\mathrm{d}=2.05)$. In contrast, one variable (sprint performance in the Agility T-test) showed no relevant effect size $(\mathrm{d}=0.41)$ in the CT. The largest interaction effects were obtained for distance in the Yo-Yo IR1 $\left(p<0.001, \eta^{2}=0.789\right.$; Figure 1), 1RM in the bench press $\left(p<0.001, \eta^{2}=\right.$ $0.700)$ and $1 \mathrm{RM}$ in the half squat $\left(p<0.001, \eta^{2}=\right.$ 0.640; Figure 2).

On the other hand, the lowest interaction effect was detected for $15 \mathrm{~m}$ sprint performance $(p$ $=0.317, \eta^{2}=0.059$; Figure 3). In the control group, three relevant $(\mathrm{d} \geq-0.5)$ performance decreases (Agility T-test: $\mathrm{d}=-0.73$; distance Yo-Yo IR1: $\mathrm{d}=$ $0.70 ; 30 \mathrm{~m}$ sprint: $\mathrm{d}=-0.50$ ) were observed (Table 3). In general, all effect sizes ranged between -0.73 (Agility T-test) and 0.29 (CMJ height; Figure 4).

In contrast, effect sizes in the CT moved from 0.41 (Agility T-test) to 2.76 (distance Yo-Yo IR1). Overall, the effectiveness of training over the intervention period was significantly poorer for the CG than for the CT ( $\varnothing \mathrm{d}_{\mathrm{CG}}=-1.02 \mathrm{vs} . \varnothing \mathrm{d}_{\mathrm{CT}}=1.30$ ). No relevant improvements were observed in the CG and no relevant performance decreases were found in the CT.

\section{Discussion}

The aim of our study was to compare the effects of circuit training on maximal strength, sprint ability, agility, high intensity aerobic ability, and vertical jump performance in male handball players at a critical phase in their playing season. The findings indicate that a circuit training program can effectively improve these characteristics of handball players compared to a standard regimen. 
Table 1

12-week circuit training intervention.

\begin{tabular}{|c|c|c|c|c|c|c|}
\hline Exercises & Session 1 & Session 2 & Session 3 & Session 4 & Session 5 & Session 6 \\
\hline Multiple diagonal & $\begin{array}{c}10 \text { jumps / } 40 \\
\mathrm{~cm} \text { high }\end{array}$ & $\begin{array}{c}10 \text { jumps / } 40 \\
\mathrm{~cm} \text { high }\end{array}$ & $\begin{array}{c}10 \text { jumps / } 40 \\
\mathrm{~cm} \text { high }\end{array}$ & $\begin{array}{c}10 \text { jumps / } 40 \\
\text { cm high }\end{array}$ & $\begin{array}{c}10 \text { jumps / } 40 \\
\text { cm high }\end{array}$ & $\begin{array}{c}10 \text { jumps / } 40 \\
\text { cm high }\end{array}$ \\
\hline $\begin{array}{l}\text { Medicine ball } \\
\text { throw }\end{array}$ & 10 throw $/ 3 \mathrm{~kg}$ & 10 throw $/ 3 \mathrm{~kg}$ & 12 throw $/ 3 \mathrm{~kg}$ & 13 throw $/ 3 \mathrm{~kg}$ & 13 throw $/ 3 \mathrm{~kg}$ & 12 throw/ $3 \mathrm{~kg}$ \\
\hline $\begin{array}{l}\text { CMJ Depth jumps } \\
\text { "box onto box" }\end{array}$ & $\begin{array}{l}10 \text { jumps / } 50 \\
\mathrm{~cm} \text { high }\end{array}$ & $\begin{array}{l}10 \text { jumps / } 50 \\
\mathrm{~cm} \text { high }\end{array}$ & $\begin{array}{l}10 \text { jumps / } 50 \\
\mathrm{~cm} \text { high }\end{array}$ & $\begin{array}{l}10 \text { jumps / } 50 \\
\text { cm high }\end{array}$ & $\begin{array}{c}10 \text { jumps / } 50 \mathrm{~cm} \\
\text { high }\end{array}$ & $\begin{array}{c}12 \text { jumps } / 50 \mathrm{~cm} \\
\text { high }\end{array}$ \\
\hline half back-squat & $60: 3 \times 6$ & $60: 3 \times 6$ & $60: 3 \times 6$ & $60: 3 \times 8$ & $60: 3 \times 8$ & $60: 3 \times 8$ \\
\hline Zig zag sprint & $4 \times 5 \mathrm{~m}(20 \mathrm{~m})$ & $4 \times 5 \mathrm{~m}(20 \mathrm{~m})$ & $4 \times 5 \mathrm{~m}(20 \mathrm{~m})$ & $4 \times 5 \mathrm{~m}(20 \mathrm{~m})$ & $4 \times 5 \mathrm{~m}(20 \mathrm{~m})$ & $4 \times 5 \mathrm{~m}(20 \mathrm{~m})$ \\
\hline 1RM Pull-over & $60: 3 \times 6$ & $60: 3 \times 6$ & $60: 3 \times 6$ & $60: 3 \times 8$ & $60: 3 \times 8$ & $60: 3 \times 8$ \\
\hline Exercises & Session 7 & Session 8 & Session 9 & Session 10 & Session 11 & Session 12 \\
\hline Multiple diagonal & $\begin{array}{l}12 \text { jumps / } 40 \\
\mathrm{~cm} \text { high }\end{array}$ & $\begin{array}{l}12 \text { jumps / } 40 \\
\mathrm{~cm} \text { high }\end{array}$ & $\begin{array}{c}12 \text { jumps / } 40 \\
\mathrm{~cm} \text { high }\end{array}$ & $\begin{array}{l}12 \text { jumps / } 40 \\
\text { cm high }\end{array}$ & $\begin{array}{c}12 \text { jumps / } 40 \mathrm{~cm} \\
\text { high }\end{array}$ & $\begin{array}{c}12 \text { jumps / } 40 \mathrm{~cm} \\
\text { high }\end{array}$ \\
\hline $\begin{array}{l}\text { Medicine ball } \\
\text { throw }\end{array}$ & 14 throw $/ 3 \mathrm{~kg}$ & 12 throw $/ 3 \mathrm{~kg}$ & 12 throw $/ 3 \mathrm{~kg}$ & 12 throw $/ 3 \mathrm{~kg}$ & 12 throw $/ 3 \mathrm{~kg}$ & 12 throw $/ 3 \mathrm{~kg}$ \\
\hline $\begin{array}{l}\text { CMJ Depth jumps } \\
\text { "box onto box" }\end{array}$ & $\begin{array}{c}12 \text { jumps / } 50 \\
\mathrm{~cm} \text { high }\end{array}$ & $\begin{array}{l}12 \text { jumps / } 50 \\
\mathrm{~cm} \text { high }\end{array}$ & $\begin{array}{c}12 \text { jumps / } 50 \\
\mathrm{~cm} \text { high }\end{array}$ & $\begin{array}{l}12 \text { jumps / } 50 \\
\text { cm high }\end{array}$ & $\begin{array}{c}12 \text { jumps / } 50 \mathrm{~cm} \\
\text { high }\end{array}$ & $\begin{array}{c}12 \text { jumps } / 50 \mathrm{~cm} \\
\text { high }\end{array}$ \\
\hline half back-squat & $70: 3 \times 6$ & $70: 3 \times 6$ & $70: 3 \times 8$ & $70: 3 \times 8$ & $70: 3 \times 8$ & $70: 3 \times 8$ \\
\hline Zig zag sprint & $4 \times 5 \mathrm{~m}(20 \mathrm{~m})$ & $4 \times 5 \mathrm{~m}(20 \mathrm{~m})$ & $4 \times 5 \mathrm{~m}(20 \mathrm{~m})$ & $4 \times 5 \mathrm{~m}(20 \mathrm{~m})$ & $4 \times 5 \mathrm{~m}(20 \mathrm{~m})$ & $4 \times 5 \mathrm{~m}(20 \mathrm{~m})$ \\
\hline 1RM Pull-over & $70: 3 \times 6$ & $70: 3 \times 6$ & $70: 3 \times 6$ & $70: 3 \times 8$ & $70: 3 \times 6$ & $70: 3 \times 8$ \\
\hline Exercises & Session 13 & Session 14 & Session 15 & Session 16 & Session 17 & Session 18 \\
\hline $\begin{array}{l}\text { CMJ Frontal jumps } \\
\text { over barrier }\end{array}$ & $\begin{array}{c}14 \text { jumps / } 40 \\
\mathrm{~cm} \text { high }\end{array}$ & $\begin{array}{c}14 \text { jumps / } 40 \\
\mathrm{~cm} \text { high }\end{array}$ & $\begin{array}{c}14 \text { jumps / } 40 \\
\mathrm{~cm} \text { high }\end{array}$ & $\begin{array}{c}14 \text { jumps / } 40 \\
\mathrm{~cm} \text { high }\end{array}$ & $\begin{array}{c}14 \text { jumps / } 40 \mathrm{~cm} \\
\text { high }\end{array}$ & $\begin{array}{c}14 \text { jumps / } 40 \mathrm{~cm} \\
\text { high }\end{array}$ \\
\hline $\begin{array}{l}\text { Medicine ball } \\
\text { throw }\end{array}$ & 12 throw $/ 3 \mathrm{~kg}$ & 14 throw $/ 3 \mathrm{~kg}$ & 12 throw $/ 3 \mathrm{~kg}$ & 14 throw $/ 3 \mathrm{~kg}$ & 12 throw $/ 3 \mathrm{~kg}$ & 14 throw/ $3 \mathrm{~kg}$ \\
\hline $\begin{array}{l}\text { CMJ Depth jumps } \\
\text { "box onto box" }\end{array}$ & $\begin{array}{c}14 \text { jumps / } 50 \\
\mathrm{~cm} \text { high }\end{array}$ & $\begin{array}{l}14 \text { jumps / } 50 \\
\mathrm{~cm} \text { high }\end{array}$ & $\begin{array}{l}14 \text { jumps / } 50 \\
\mathrm{~cm} \text { high }\end{array}$ & $\begin{array}{c}14 \text { jumps / } 50 \\
\mathrm{~cm} \text { high }\end{array}$ & $\begin{array}{c}14 \text { jumps / } 50 \mathrm{~cm} \\
\text { high }\end{array}$ & $\begin{array}{c}14 \text { jumps / } 50 \mathrm{~cm} \\
\text { high }\end{array}$ \\
\hline half back-squat & $70: 3 \times 10$ & $70: 3 \times 10$ & $70: 3 \times 10$ & $70: 3 \times 10$ & $70: 3 \times 10$ & $70: 3 \times 10$ \\
\hline Zig zag sprint & $4 \times 5 \mathrm{~m}(20 \mathrm{~m})$ & $4 \times 5 \mathrm{~m}(20 \mathrm{~m})$ & $4 \times 5 \mathrm{~m}(20 \mathrm{~m})$ & $4 \times 5 \mathrm{~m}(20 \mathrm{~m})$ & $4 \times 5 \mathrm{~m}(20 \mathrm{~m})$ & $4 \times 5 \mathrm{~m}(20 \mathrm{~m})$ \\
\hline 1RM Pull-over & $70: 3 \times 10$ & $70: 3 \times 10$ & $70: 3 \times 10$ & $70: 3 \times 10$ & $70: 3 \times 10$ & $70: 3 \times 10$ \\
\hline Exercises & Session 19 & Session 20 & Session 21 & Session 22 & Session 23 & Session 24 \\
\hline $\begin{array}{l}\text { CMJ Frontal jumps } \\
\text { over barrier }\end{array}$ & $\begin{array}{c}16 \text { jumps / } 40 \\
\mathrm{~cm} \text { high }\end{array}$ & $\begin{array}{c}16 \text { jumps / } 40 \\
\mathrm{~cm} \text { high }\end{array}$ & $\begin{array}{l}16 \text { jumps / } 40 \\
\mathrm{~cm} \text { high }\end{array}$ & $\begin{array}{c}16 \text { jumps / } 40 \\
\mathrm{~cm} \text { high }\end{array}$ & $\begin{array}{c}16 \text { jumps / } 40 \mathrm{~cm} \\
\text { high }\end{array}$ & $\begin{array}{c}16 \text { jumps / } 40 \mathrm{~cm} \\
\text { high }\end{array}$ \\
\hline $\begin{array}{l}\text { Medicine ball } \\
\text { throw }\end{array}$ & 12 throw $/ 3 \mathrm{~kg}$ & 16 throw $/ 3 \mathrm{~kg}$ & 12 throw $/ 3 \mathrm{~kg}$ & 16 throw $/ 3 \mathrm{~kg}$ & 12 throw $/ 3 \mathrm{~kg}$ & 16 throw $/ 3 \mathrm{~kg}$ \\
\hline $\begin{array}{l}\text { CMJ Depth jumps } \\
\text { "box onto box" }\end{array}$ & $\begin{array}{c}16 \text { jumps / } 50 \\
\mathrm{~cm} \text { high }\end{array}$ & $\begin{array}{l}16 \text { jumps / } 50 \\
\mathrm{~cm} \text { high }\end{array}$ & $\begin{array}{l}16 \text { jumps / } 50 \\
\mathrm{~cm} \text { high }\end{array}$ & $\begin{array}{c}16 \text { jumps / } 50 \\
\mathrm{~cm} \text { high }\end{array}$ & $\begin{array}{c}16 \text { jumps / } 50 \mathrm{~cm} \\
\text { high }\end{array}$ & $\begin{array}{c}16 \text { jumps } / 50 \mathrm{~cm} \\
\text { high }\end{array}$ \\
\hline half back-squat & $75: 3 \times 8$ & $75: 3 \times 8$ & $75: 3 \times 8$ & $75: 3 \times 8$ & $75: 3 \times 10$ & $75: 3 \times 10$ \\
\hline Zig zag sprint & $4 \times 5 \mathrm{~m}(20 \mathrm{~m})$ & $4 \times 5 \mathrm{~m}(20 \mathrm{~m})$ & $4 \times 5 \mathrm{~m}(20 \mathrm{~m})$ & $4 \times 5 \mathrm{~m}(20 \mathrm{~m})$ & $4 \times 5$ me $(20 \mathrm{~m})$ & $4 \times 5 \mathrm{~m}(20 \mathrm{~m})$ \\
\hline 1RM Pull-over & $75: 3 \times 8$ & $75: 3 \times 8$ & $70: 3 \times 8$ & $75: 3 \times 8$ & $75: 3 \times 10$ & $75: 3 \times 10$ \\
\hline
\end{tabular}

Zig zag sprint: with $110^{\circ}$ curves; Multiple diagonal: cone hops 
Table 2

Comparison of baseline test measurements and post-intervention values in the studied handball players $(n=19)$. Descriptive statistics (mean $\pm S D)$ and intrarater reliability analysis calculated for each test are presented. ICC $\geq 0.75$ and $C V \leq 5 \%$ are highlighted in bold.

$\begin{array}{cccccc}\text { test } & \begin{array}{c}\text { Session one } \\ \text { mean } \pm \text { SD }\end{array} & \begin{array}{c}\text { Session two } \\ \text { mean } \pm \text { SD }\end{array} & \begin{array}{c}\text { ICC } \\ (95 \% \mathrm{CI})\end{array} & \text { SEM } & \begin{array}{c}\text { CV (\%) } \\ (95 \% \mathrm{CI})\end{array}\end{array}$

\begin{tabular}{lllllc}
\hline Squat jump $(\mathrm{cm})$ & $39.9 \pm 2.80$ & $39.8 \pm 2.94$ & $\mathbf{0 . 9 5}(0.86-0.98)$ & 0.66 & $\mathbf{2 . 4}(1.8-3.6)$ \\
$\begin{array}{l}\text { Countermovement } \\
\text { jump }(\mathrm{cm})\end{array}$ & $43.0 \pm 1.96$ & $43.1 \pm 1.94$ & $\mathbf{0 . 8 6}(0.65-0.95)$ & 0.73 & $\mathbf{2 . 3}(1.7-3.4)$ \\
& & & & & \\
15 m Sprint (s) & $2.59 \pm 0.18$ & $3.00 \pm 0.19$ & $\mathbf{0 . 8 7}(0.65-0.95)$ & 1.95 & $\mathbf{3 . 5}(2.7-5.3)$ \\
30 m Sprint (s) & $4.36 \pm 0.17$ & $4.32 \pm 0.16$ & $\mathbf{0 . 9 6}(0.86-0.99)$ & 0.03 & $\mathbf{1 . 0}(0.7-1.5)$ \\
Agility T-test (s) & $6.15 \pm 0.30$ & $6.23 \pm 0.24$ & $0.72(0.29-0.89)$ & 0.14 & $\mathbf{2 . 9}(2.3-4.5)$ \\
Bench press (kg) & $79.1 \pm 10.6$ & $78.2 \pm 7.49$ & $\mathbf{0 . 8 9}(0.71-0.96)$ & 3.00 & $5.4(4.1-8.3)$ \\
Pull over $(\mathrm{kg})$ & $42.6 \pm 6.88$ & $43.0 \pm 4.81$ & $\mathbf{0 . 8 5}(0.60-0.94)$ & 2.26 & $7.7(6.0-12.1)$
\end{tabular}

Table 3

Descriptive comparison of the circuit training group and the control group before and after the 12-week intervention. Relevant effect sizes are highlighted in bold.

\begin{tabular}{|c|c|c|c|c|c|c|}
\hline \multirow{3}{*}{ Variable } & \multicolumn{3}{|c|}{ Experimental group (Mean \pm SD) } & \multicolumn{3}{|c|}{ Control group (Mean \pm SD) } \\
\hline & Pre & Post & & Pre & Post & \\
\hline & \multicolumn{5}{|c|}{ d } & d \\
\hline & \multicolumn{6}{|c|}{ Anthropometry } \\
\hline Body mass $(\mathrm{kg})$ & $90.5 \pm 13.2$ & $88.9 \pm 13.3$ & 0.12 & $85.3 \pm 16.3$ & $82.3 \pm 14.5$ & 0.20 \\
\hline \multirow[t]{2}{*}{ Fat mass $(\%)$} & $17.9 \pm 4.33$ & $15.7 \pm 3.59$ & 0.56 & $16.2 \pm 4.66$ & $14.9 \pm 2.57$ & 0.36 \\
\hline & \multicolumn{6}{|c|}{ Sprint performance (s) } \\
\hline Sprint $15 \mathrm{~m}$ & $2.57 \pm 0.18$ & $2.47 \pm 0.15$ & 0.61 & $2.61 \pm 0.20$ & $2.58 \pm 0.18$ & 0.16 \\
\hline Sprint $30 \mathrm{~m}$ & $4.25 \pm 0.13$ & $4.15 \pm 0.22$ & 0.57 & $4.48 \pm 0.13$ & $4.55 \pm 0.15$ & -0.50 \\
\hline \multirow[t]{2}{*}{ Agility T-test } & $6.16 \pm 0.26$ & $6.00 \pm 0.53$ & 0.41 & $6.13 \pm 0.36$ & $6.35 \pm 0.24$ & -0.73 \\
\hline & \multicolumn{6}{|c|}{ Jump performance $(\mathrm{cm})$} \\
\hline CMJ height & $43.4 \pm 1.71$ & $46.8 \pm 1.77$ & 1.95 & $42.4 \pm 2.19$ & $43.0 \pm 1.94$ & 0.29 \\
\hline \multirow[t]{2}{*}{ SJ height } & $39.8 \pm 3.17$ & $44.6 \pm 1.51$ & 2.05 & $38.7 \pm 4.09$ & $39.4 \pm 3.94$ & 0.17 \\
\hline & \multicolumn{6}{|c|}{ 1RM (kg) } \\
\hline Half squat & $162 \pm 33.2$ & $185 \pm 26.9$ & 0.77 & $156 \pm 36.0$ & $153 \pm 38.1$ & -0.03 \\
\hline Bench-press & $83.0 \pm 10.6$ & $98.1 \pm 10.7$ & 1.42 & $74.7 \pm 9.27$ & $76.7 \pm 12.8$ & 0.18 \\
\hline \multirow[t]{2}{*}{ Pull-over } & $44.4 \pm 7.15$ & $54.2 \pm 9.58$ & 1.17 & $40.6 \pm 6.35$ & $42.6 \pm 10.3$ & 0.24 \\
\hline & \multicolumn{6}{|c|}{ Yo-Yo-Intermittent Recovery Test (m) } \\
\hline Distance & $1.156 \pm 261$ & $1.956 \pm 318$ & 2.76 & $1.333 \pm 272$ & $1.129 \pm 312$ & -0.70 \\
\hline
\end{tabular}


Table 4

Comparison (a two-factor (time, group) univariate general linear model) of the circuit training group and the control group before and after the 12-week intervention.

Significant interaction effects are highlighted in bold.

\begin{tabular}{|c|c|c|c|c|c|c|}
\hline \multirow{3}{*}{ Variable } & \multicolumn{6}{|c|}{ Variance analysis/ effects } \\
\hline & \multicolumn{2}{|c|}{ Group } & \multicolumn{2}{|c|}{ Time } & \multicolumn{2}{|c|}{ Group $x$ time } \\
\hline & $\mathrm{p}$ & $\eta^{2}$ & $\mathbf{p}$ & $\eta^{2}$ & $p$ & $\eta^{2}$ \\
\hline & \multicolumn{6}{|c|}{ Anthropometry } \\
\hline Body mass $(\mathrm{kg})$ & 0.392 & 0.043 & 0.041 & 0.222 & 0.648 & 0.013 \\
\hline \multirow[t]{2}{*}{ Fat mass (\%) } & 0.478 & 0.030 & 0.001 & 0.457 & 0.341 & 0.053 \\
\hline & \multicolumn{6}{|c|}{ Sprint performance (s) } \\
\hline Sprint $15 \mathrm{~m}$ & 0.320 & 0.058 & 0.105 & 0.147 & 0.317 & 0.059 \\
\hline Sprint $30 \mathrm{~m}$ & $<0.001$ & 0.555 & 0.555 & 0.021 & 0.007 & 0.355 \\
\hline \multirow[t]{2}{*}{ Agility T-test } & 0.295 & 0.064 & 0.711 & 0.008 & 0.020 & 0.279 \\
\hline & \multicolumn{6}{|c|}{ Jump performance $(\mathrm{cm})$} \\
\hline CMJ height & 0.011 & 0.327 & $<0.001$ & 0.741 & $<0.001$ & 0.596 \\
\hline \multirow[t]{2}{*}{ SJ height } & 0.041 & 0.223 & $<0.001$ & 0.649 & 0.001 & 0.489 \\
\hline & \multicolumn{6}{|c|}{ 1RM (kg) } \\
\hline Half squat & 0.224 & 0.086 & 0.001 & 0.496 & $<0.001$ & 0.640 \\
\hline Bench-press & 0.007 & 0.353 & $<0.001$ & 0.799 & $<0.001$ & 0.700 \\
\hline \multirow[t]{2}{*}{ Pull-over } & 0.054 & 0.202 & $<0.001$ & 0.620 & 0.003 & 0.417 \\
\hline & \multicolumn{6}{|c|}{ Yo-Yo-Intermittent Recovery Test (m) } \\
\hline Distance & 0.014 & 0.308 & $<0.001$ & 0.568 & $<0.001$ & 0.789 \\
\hline
\end{tabular}

$C M J=$ countermovement jump; $S J=$ squat jump; $1 R M=$ one repetition maximum .

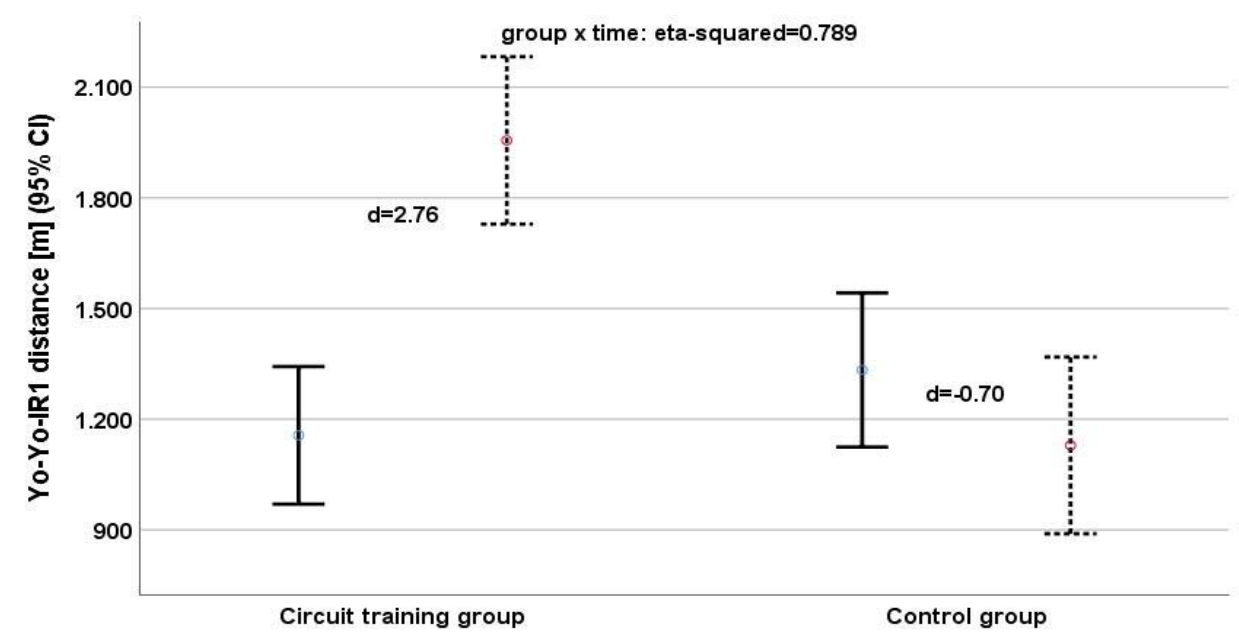

Figure 1

Test performance for the Yo-Yo-IR1. Solid line = pre-intervention test, dashed line = postintervention test. Effect size d for each group (plus means improvement, minus means deterioration) and interaction effect (group $x$ time) are given. 


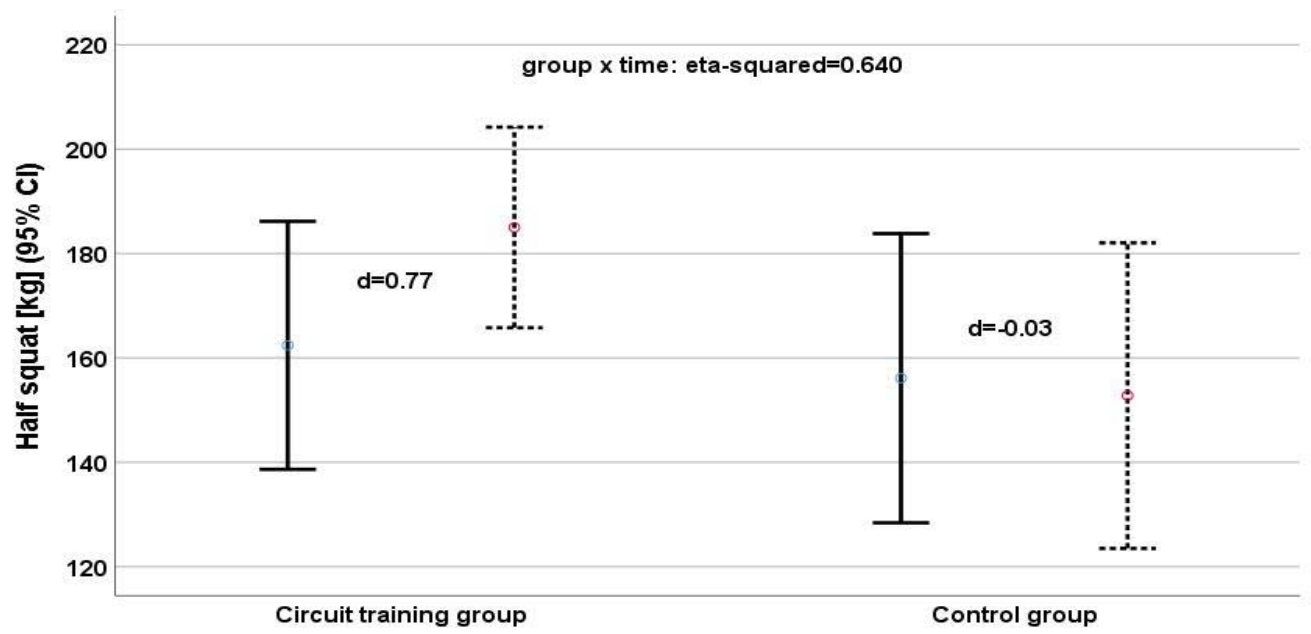

Figure 2

Test performance for the half squat. Solid line $=$ pre-intervention test, dashed line $=$ post intervention test. Effect size d for each group (plus means improvement, minus means deterioration) and interaction effect (group $x$ time) are given.

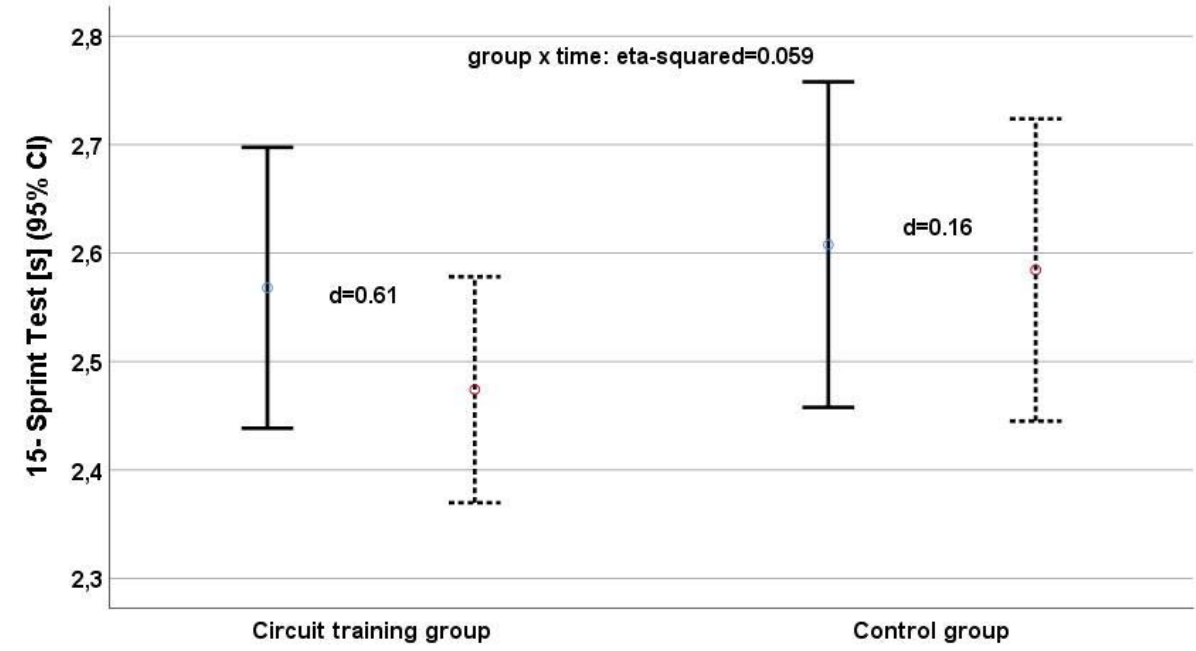

Figure 3

Test performance for the $15 \mathrm{~m}$ sprint. Solid line = pre-intervention test, dashed line = postintervention test. Effect size d for each group (plus means improvement, minus means deterioration) and interaction effect (group $x$ time) are given. 


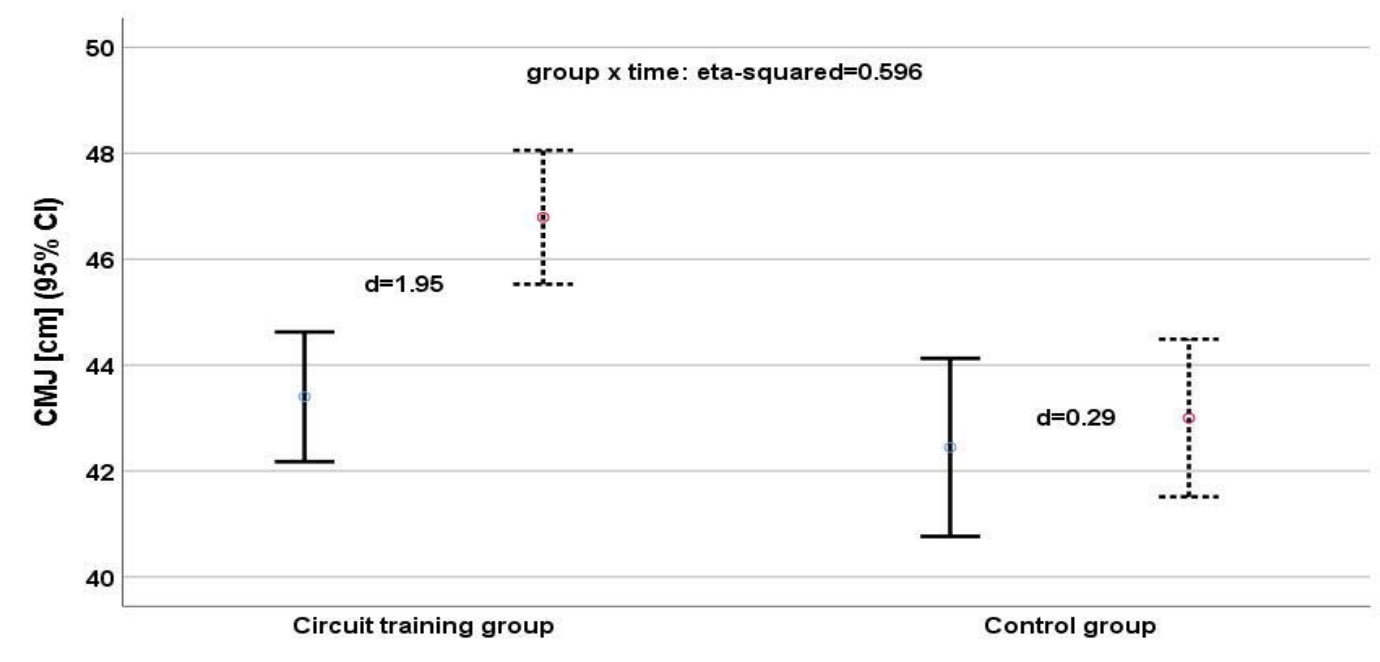

Figure 4

Test performance for the CMJ. Solid line $=$ pre-intervention test, dashed line $=$ postintervention test. Effect size d for each group (plus means improvement, minus means deterioration) and interaction effect (group $x$ time) are given.

The dynamic loads used during the circuit training program seem well suited to maximize strength (Hermassi et al., 2017; Fieseler et al., 2017; Hermassi et al., 2011) by initiating feedback reflexes from the Golgi tendon organs and improving synchronization of motor units (Gorostiaga et al., 2005). Many authors have replicated the findings of Gorostiaga et al. (2005) who showed that specific resistance training improved strength in both the upper extremities $(23 \% ; \mathrm{p}<0.01)$ and the leg extensors $(12.2 \% ; \mathrm{p}<$ $0.01)$. In our study, gains for the upper and lower limbs (circuit training: $18.5 \%$ and $15.2 \%$ for the bench-press and half-squat, respectively) were even larger than those observed by Gorostiaga et al. (2005) and Hermassi et al. (2011) possibly because of differences in the initial level of physical fitness of the players or the choice of training exercises. Hoffman et al. (2004) also reported significant increases in the 1RM back-squat, but no significant increases in 1RM bench-press scores of young athletes after 15 weeks of weightlifting training. Our study found gains in vertical jump height (7.8 and $12.5 \%$ for the CMJ and SJ, respectively), similar to those seen in handball players (Gorostiaga et al., 1999) and junior soccer players ( $7.5 \%$ and $10 \%$, respectively) (Chelly et al., 2009).

Christou et al. (2006) found gains of $13.5 \%$ and $14.4 \%$ in the squat and CMJ scores of soccer players over 8 weeks of strength training. Conversely, Gorostiaga et al. (2005) found significant increases in the CMJ height of handball players who engaged in standard team practice (6\%; $p<0.001)$, whereas resistance training and control groups showed no change. Hermassi et al. 
(2011) found a large improvement in the squat jump ( $\mathrm{p}<0.001)$, but the CMJ remained unchanged. In contrast, significant $(12 \% ; p<0.01)$ improvements in $\mathrm{CMJ}$ height were observed in controls, underlining the contention that the introduction of circuit resistance strength training does not interfere with jumping performance.

The likely explanation for the improved jump performance is that the necessary muscular coordination can only be maximized by using loads that resemble the required skill in terms of movement, speed and pattern. A heavy general leg exercise such as the squat is relatively more effective for developing intramuscular coordination, whereas loaded squat jumps are more effective in developing inter muscular coordination (Crewther et al., 2005).

To our knowledge, our study is the first to have examined the effects of circuit training on the agility of handball players. Our results showed significant improvements in the circuit training group compared to controls. Kvorning et al. (2017) examined the effect of a strength and conditioning program carried out by the Danish national handball team before the Beijing Olympic Games. Eight weeks of training improved agility by $2.5 \%$ $(p<0.05)$. Previous research concerning the impact of strength and resistance training on agility has shown both increases (Garcia-Pinillos et al., 2014; Kvorning et al., 2017) and decreases in this ability (Harris et al., 2000). Inter-study differences in reported responses to strength and conditioning training may reflect test choice (length, duration, number and angle of change of direction, and requirements of running, i.e., forward or backward), the type of subjects (youth or adults, men or women, amateur or professional), and the content of the training program (intensity, duration, number of sessions per week).

Sprinting and acceleration are important qualities for handball players (Gorostiaga et al., 2005; Hermassi et al., 2017). Any improvements after strength training may reflect both neural adaptations and alterations in the mechanical characteristics of the muscle-tendon complex, including muscle size and architecture as well as changes in single-fiber mechanics (Gorostiaga et al., 2005). Helland et al. (2016) detected no significant increase in $30 \mathrm{~m}$ sprint times after eight weeks of tri-weekly weightlifting training when compared to a power training group. Likewise,
Hoffman et al. (2004) saw no significant increase in the $30 \mathrm{~m}$ sprint time of young athletes after 15 weeks of weightlifting training, 4 times per week.

The results of our study should be interpreted cautiously due to the relatively small sample size. Furthermore, there remains a need to extend the present observations to players of other ages and skill levels, including female participants, and to analyze differences in response to this type of training by a playing position.

The increases in performance that were demonstrated can contribute to valuable knowledge for handball coaches because performance in this sport relies greatly on strength and power of the lower limbs. Yet, the significant improvements in most of the tested variables may be due to the low skill level of our participants. It may also be practical to incorporate a circuit training component into traditional in-season technical and tactical training sessions, leading to gains in the playing potential of handball players.

\section{Conclusions}

Our results show that male handball players can substantially enhance their power, sprinting ability, strength, and change of direction ability if they replace part of their standard regimen with a 12 week (2 sessions per week) inseason program of circuit training. Circuit training offers a stimulus that is uniquely different from power training, and it should be considered a part of any resistance training program for handball players, who require quick, powerful movements. In a practical sense, coaches might prefer to use a hierarchical lifting program when there is a need to improve power, strength, sprint, change of direction ability and throwing velocity, all of which were enhanced by this type of training. Based on our results we recommend that handball coaches consider incorporating in-season circuit training into the schedule of their players, as a simple and practical method to enhance their performance. We would also encourage further investigation of the many potential neuromuscular mechanisms underlying the observed gains in performance. 


\section{Acknowledgements}

Special thanks to all handball players and coaches for their valuable help and involvement in this study. This work was supported by the Sport Science Program, College of Arts and Sciences, Qatar University, Doha, Qatar.

\section{References}

Bortz J. Statistics for Social Scientists. Berlin, Heidelberg, New York: Springer; 1999th

Chelly MS, Fathloun M, Cherif N, Ben Amar M, Tabka Z, Van Praagh E. Effects of a back squat training program on leg power, jump, and sprint performances in junior soccer players. J Strength Cond Res, 2009; 23(8): 2241-9

Chelly MS, Ghenem MA, Abid K, Hermassi S, Tabka Z, Shephard RJ. Effects of in-season short-term plyometric training program on leg power, jump- and sprint performance of soccer players. J Strength Cond Res, 2010; 24(10): 2670-6

Christou M, Smilios I, Sotiropoulos K, Volaklis K, Pilianidis T, Tokmakidis SP. Effects of resistance training on the physical capacities of adolescent soccer players. J Strength Cond Res, 2006; 20(4): 783-91

Cometti G, Maffiuletti NA, Pousson M, Chatard JC, Maffulli N. Isokinetic strength and anaerobic power of elite, subelite and amateur French soccer players. Int J Sports Med, 2001; 22(1): 45-51

Crewther B, Cronin J, Keogh J. Possible stimuli for strength and power adaptation: acute mechanical responses. Sports Med, 2005; 35(11): 967-89

Garcia-Pinillos F, Martinez-Amat A, Hita-Contreras F, Martinez-Lopez EJ, Latorre-Roman PA. Effects of a contrast training program without external load on vertical jump, kicking speed, sprint, and agility of young soccer players. J Strength Cond Res, 2014; 28(9): 2452-60

Fieseler G, Hermassi S, Hoffmeyer B, Schulze S, Irlenbusch L, Bartels T, Delank KS, Laudner KG, Schwesig R. Differences in anthropometric characteristics in relation to throwing velocity and competitive level in professional male team handball: a tool for talent profiling. J Sports Med Phys Fitness, 2017; 57(7-8): 985992

Gorostiaga EM, Izquierdo M, Iturralde P, Ruesta M, Ibanez J. Effects of heavy resistance training on maximal and explosive force production, endurance and serum hormones in adolescent handball players. Eur J Appl Physiol Occup Physiol, 1999; 80(5): 485-93

Gorostiaga EM, Granados C, Ibanez J, Izquierdo M. Differences in physical fitness and throwing velocity among elite and amateur male handball players. Int J Sports Med, 2005; 26(3): 225-32

Harris G, Stone M, O'Bryant HS, Proulx CM, Johnson RL. Short-Term Performance Effects of High Power, High Force, or Combined Weight-Training Methods. J Strength Cond Res, 2000;14(1): 14-20

Helland C1, Hole E, Iversen E, Olsson MC, Seynnes O, Solberg PA, Paulsen G. Training Strategies to Improve Muscle Power: Is Olympic-style Weightlifting Relevant? Med Sci Sports Exerc, 2017; 49(4): 736-45

Hermassi S, Chelly MS, Fathloun M, Shephard RJ. The effect of heavy- vs. moderate-load training on the development of strength, power, and throwing ball velocity in male handball players. J Strength Cond Res, 2010; 24(9): 2408-18

Hermassi S, Chelly MS, Fieseler G, Bartels T, Schulze S, Delank KS, Shepard RJ, Schwesig R. Short-Term Effects of Combined High-Intensity Strength and Sprint Interval Training on Anthropometric Characteristics and Physical Performance of Elite Team Handball Players. Sportverletz Sportschaden, 2017; 31(4): 231-9

Hermassi S, Chelly MS, Tabka Z, Shephard RJ, Chamari K. Effects of 8-week in-season upper and lower limb heavy resistance training on the peak power, throwing velocity, and sprint performance of elite male handball players. J Strength Cond Res, 2011; 25(9): 2424-33

Herrero JA, Izquierdo M, Maffiuletti NA, Garcia-Lopez J. Electromyostimulation and plyometric training effects on jumping and sprint time. Int J Sports Med, 2006; 27(7): 533-9

Hoffman JR, Cooper J, Wendell M, Kang J. Comparison of Olympic vs. traditional power lifting training programs in football players. J Strength Cond Res, 2004; 18(1): 129-35

Hopkins W. Measures of reliability in sports medicine and science. Sports Med, 2000; 30(1): 1-15

Hopker J, Myers S, Jobson SA, Bruce W, Passfield L. Validity and reliability of the Wattbike cycle ergometer. Int J Sports Med, 2010; 31(10): 731-736 
Krustrup P, Mohr M, Amstrup T, Rysgaard T, Johansen J, Steensberg A, Pedersen PK, Bangsbo J. The yo-yo intermittent recovery test: physiological response, reliability, and validity. Med Sci Sports Exerc, 2003; 35(4): 697-705

Kvorning T, Hansen MRB, Jensen K. Strength and Conditioning Training by the Danish National Handball Team Before an Olympic Tournament. J Strength Cond Res, 2017; 31(7): 1759-65

Maio Alves JM, Rebelo AN, Abrantes C, Sampaio J. Short-term effects of complex and contrast training in soccer players' vertical jump, sprint, and agility abilities. J Strength Cond Res, 2010; 24(4): 936-41

Portney LG, Watkins MP. Foundations of Clinical Research: Applications to Practice. 2009. 3 ${ }^{\text {rd }}$ ed. NJ: Pearson Prentice Hall, Upper Saddle River.

Sassi RH, Dardouri W, Yahmed MH, Gmada N, Mahfoudhi ME, Gharbi Z. Relative and absolute reliability of a modified agility T-test and its relationship with vertical jump and straight sprint. J Strength Cond Res, 2009; 23(6): 1644-51

Schrama PP, Stenneberg MS, Lucas C, van Trijffel E. Intraexaminer reliability of hand-held dynamometry in the upper extremity: a systematic review. Arch Phys Med Rehabil, 2014; 95(12): 2444-2469

Shrout PE, Fleiss JL. Intraclass correlations: Uses in assessing rater reliability. Psychol Bull, 1979; 86(2): 420-428

Wilson GJ, Newton RU, Murphy AJ, Humphries BJ. The optimal training load for the development of dynamic athletic performance. Med Sci Sports Exerc, 1993; 25(11): 1279-86

Weir JP. Quantifying test-retest reliability using the intraclass correlation coefficient and the SEM. J Strength Cond Res, 2005; 19(1): 231-240

\section{Corresponding author:}

\section{Souhail Hermassi, Ph, D.}

Sport Science Program, College of Arts and Sciences,

Qatar University, Doha, Qatar.

E-mail: shermassi@qu.edu.qa

Phone: +974 30511166 